\title{
1. Decentralization in the Middle East and North Africa: The Puzzle
}

\author{
Thomas Demmelhuber and Roland Sturm
}

Every country in the world needs a subnational governmental level - local, regional, or both - to administer policies. Decentralization has accordingly been in the limelight of scholarly debate both for OECD countries and for other world regions such as the Middle East and North Africa (MENA) for the last decades. For the MENA region this is a surprising finding as the states of the region were once considered "the most centralized in the world" (Kherigi 2017, 4). This debate on decentralization centers not only on the regionalization of policy implementation, but also on the political impact of the center on all subnational levels. Depending on the quality of a state's center-periphery relations, either the periphery's influence may shape the political structure to favor a federal or strongly decentralized state (bottom-up decentralization), or it may inspire the center to strive for the periphery's de-politicization and to uphold the control of the periphery (top-down decentralization). Decentralization initiated by the center (topdown) is especially vulnerable to political games by autocratic regimes: As autocratic power holders pretend to improve democratic representation by de jure decentralization, they may delegate the "right to act", but remain hesitant to accept a subnational "right to decide"

The transfer of rule from the central government level to regional and local levels leaves room for a variety of different scenarios for political, constitutional, and cultural change. It moreover offers a wide array of possibilities for political instrumentalization, both to the benefit of political elites in the capital and to actors involved at the regional and local levels. All actors fight over decentralization for the same reasons: They fight over the access, design, and output of state institutions, as meaningful decentralization changes the basic parameters and setup of state power and authority (Eaton, Kaiser, and Smoke 2010, 1).

Political and academic debate on decentralization - which is but one of several forms of power-sharing between the center and the periphery broadly carries a normative bias. Although decentralization does not per se

1 For the distinction see, for example, Keman (2000, 196-227). 
undermine the dominance of the political center, decentralization is frequently assumed to be a one-way street towards a greater level of democracy and degree of good governance. We do not fundamentally question this presumption. Our research, however, aims to solve the puzzle why the results of decentralization politics differ dramatically, even though the rhetoric and motives that accompany the political phenomenon share a similar spectrum across countries and regions. We believe that in order to comprehend this discrepancy, the "menu of decentralization" must be understood within a broader setting of agency, historical context, and the respective institutional designs, in order to account for the diverse outcomes of decentralization across the MENA region over space and time. We understand decentralization as an instrument of high flexibility: In some cases it is a tool that can be displayed without being put to use, in other cases it is but a broken promise, and in yet others, decentralization is truly a first step to local empowerment.

\section{Decentralization - a story with many chapters}

When it transpired that the mass uprisings rolling over the MENA from 2011 onward mainly originated far from the capitals of the region, the limits of an approach neglecting the potential of subnational governance became evident (Hoffmann, Bouziane, and Harders 2013). This lesson on political dynamism entered the scholarly debate and ensured some diversification in approaches, perspectives, and awareness of cross-cutting issues. Yet the mainstream of MENA Political Science retained its strong central state bias. Only limited attention has since been payed to political change at subnational levels of governance (Busse and Bank 2021). The current resurgence and ongoing resilience of autocratic regimes in MENA seem to validate this traditional focus on agency and institutional design from a top-down perspective.

While local levels of government are of central interest regarding the cooperation of countries with international donors and as reference points for emerging challenges in the periphery - such as terrorist activities in border regions or transnational migration routes - the regional level of government has hardly been addressed at all. The dominating perspective on center-periphery relations is that they are binary and encompass only the relationship between the central state level and the local level. This reflects the worldview and self-perception of political elites, as well as their practice of governing from afar. Central elites permit local elites only a secondary political status. They coopt them in order to neutralize them politi- 
cally and to streamline decision-making processes. Elite rotation - orchestrated by the central state level - is an often-used mechanism to prevent elites from gaining too much power in local settings (see chapter 4). Free and fair elections at the local level with potential to undermine the grip of central state elites on the local power game are the exception rather than the rule. Instead, local elections are frequently postponed, abolished or manipulated. Autocratic regimes developed a broad toolbox for election management. It provides them with the ability to reconcile formal processes with pre-determined outcomes. In any case, only a narrow corridor for local autonomy exists.

When from 2011 onward the mass protests of the periphery spilled over to urban spaces across the region, several MENA regimes responded to the increasing uncontrollability of the political dynamics by broadening their discourse on decentralization and local governance reforms. Resilient monarchs, inter alia of Morocco and Jordan, used decentralization reforms to stabilize their grip on power. This illustrates and strengthens the argument made by Heydemann (2007) on regionalization as a form of authoritarian upgrading (Vollmann et al. 2020) instead of a serious effort to decentralize power. Reform efforts primarily targeted the mobilized sections of the population. Decentralization promised an end to wide-spread socioeconomic dichotomies and regional disparities along traditional lines of friction between the center and the periphery. In addition, the reforms addressed the international community. Widely broadcasted narratives of domestic reform aimed to communicate the sincerity of attempts to re-configure national political orders in MENA. Even the formerly heavily centralized regimes Tunisia and Egypt opted for decentralization and introduced according principles in their new constitutions. While in Tunisia, the democratic transition was successful and the ensuing reform process included substantial and challenging decentralization efforts, the re-autocratization in Egypt after two military interventions stifled all reform and decentralization processes. The today remaining structures do not deserve the label decentralization.

We conclude that despite different motives, objectives, and outcomes decentralization has become a significant policy project for many MENA governments. The states of MENA were once considered "the most centralized in the world" (Kherigi 2017, 4; Shalaby et al. 2020), which places the region in stark contrast to other world regions (Harb and Atallah 2014; 2015). Moreover, hardly any quantitative data for the scope and quality of decentralization in the MENA region is currently available (Harguindéguy, Cole, and Pasquier 2019). 
For some MENA countries, decentralization offers a strategy to foster democratic consolidation (Tunisia). For others, decentralization serves as window dressing in symbolic and orchestrated reform processes (Algeria, Oman), it enables authoritarian upgrading (Morocco, Jordan), or remains a catchphrase exploited by hard-line autocrats (Egypt). From this tentative list, it seems obvious that regime type matters for decentralization outcomes. However, the list reveals no information on diverging or overlapping content and processes of decentralization strategies. We need a deeper understanding of the reciprocal effects between elite networks and decentralization processes, in order to gain insight into the discrepancies of the legal institutional designs of decentralization and their de facto outcomes.

To regard political decentralization in MENA only through the lens of the Arab uprisings would fall short of grasping its potential, even though the tremendous increase of decentralization rhetoric and actions since 2011 affects our research. Despite the centralist traditions of all MENA states, we can observe decentralization debates and reforms in almost all MENA countries since the early 1990s. In the 1990s and 2000s, decentralization policies were implemented by top-down reforms. They were initiated by central governments in order to increase the respective regime's capacity to govern the periphery, to create (output) legitimation by increasing the efficiency and performance of their rule, and by allocating external support and funds from international donors who were the first to advocate political decentralization for the sake of fostering and/or supporting good governance. What is more, decentralization seemed to be a panacea for all political, economic, and social deadlocks, even as a tool for conflict settlement as the cases of war-torn Sudan and Lebanon have shown par excellence. Heavily endorsed by the international community, for example the World Bank, the United Nations Development Programme (UNDP), and USAID, the expectations of reform projects were high and encompassed political, social, and economic improvement. Notwithstanding the positive point of departure, the lack of coherence between objectives and strategies runs like a thread through policy implementation. How can international donors tackle the dominating conflicts between efficiency and empowerment or between empowerment and corruption?

However, the reform projects must not be understood only from a Western or an international donor's perspective. The political, economic, and social context factors in the respective countries with their varying political orders and legacies matter and are much more than an intervening variable. It has become evident that the triggers of decentralization are manifold: The strategic responsiveness of autocratic regimes targets both the populace and the international community. But what does decentral- 
ization stand for in the MENA region? How can we explain variance in decentralization processes? Who are the relevant actors behind decentralization, and how can we grasp their motives? Despite substantial research in this field, a lacuna in research exists regarding the question of how to understand the numerous challenges facing decentralization in the MENA region.

Our approach in this book is empirical. We do not accept as a normative premise that decentralization matters and we are not concerned with the question whether decentralization or centralization might be the better alternative of governance. Instead, we orient ourselves along one central assumption: The outcome of the decentralization processes driven by centerperiphery dichotomies in traditionally centralized states highly depends on the role of informal politics and neopatrimonial networks at the central, regional, and local level (first presented in Demmelhuber, Sturm, and Vollmann 2020). This applies both to the transition from a more centralized to a more decentralized state and for the stability and efficiency of institutional decentralization.

The premise of this book builds on neopatrimonial networks as an explanatory factor for the varieties in outcome of decentralization at the local and regional level. The respective objective is to provide a deeper understanding of decentralization processes correlative to their influence. Neopatrimonialism is a predominant pattern of authoritarian rule in most MENA countries. It implies a deep-rooted entanglement of modern state bureaucracy with a strong and broad-spanning net of personal relations. Neopatrimonialism - as our findings for Tunisia show - remains a constant challenge for democratization and the consolidation of democratic order. With our comparative study of Morocco, Jordan, Tunisia, and Egypt, we can present a broad perspective on the dynamics of neopatrimonialism in MENA countries and we can help generate an understanding of difficulties in and requirements to implementing decentralization reforms in the region.

The book is based on a research project funded by the German Research Foundation from 2017 to 2021. The project allowed us to pursue seven field work trips to the region and to conduct 162 interviews with politicians and state employees, civil society actors, researchers, journalists, and foreign observer organizations on the central, regional, and local govern- 
ment levels (plus five interviews with representatives of donor organizations for Sylvia Bergh's chapter). ${ }^{2}$

\section{The book's rationale and outline}

This book contributes to research on subnational governance in the Middle East and North Africa by investigating political, economic, and social links between top-down decentralization strategies and neopatrimonial elite networks for three levels of governance: the central, regional, and local levels. Based on qualitative and quantitative data, the book offers conceptual insight for the comparative study of decentralization worldwide. The book presents findings on Morocco, Jordan, Tunisia, and Egypt based on our conceptual approach and comprehensive field work. The wider framework of decentralization and the role of informal institutions, fiscal relations, and neopatrimonial networks therein is a point of departure for a new understanding of subnational governance. By deconstructing decentralization as a contested topic of an ongoing political, economic, and social debate, we provide additional insight into the puzzle of top-down decentralization and its effects. Our analysis entails a four-part agenda: (1) Understanding decentralization from the perspective of the periphery rather than the central state level, (2) evaluating how decentralization takes place in neopatrimonial and thus largely informal contexts, (3) using fiscal policy and informal financial flows to shed light on decentralization (including deviant behavior such as corruption) and (4), providing conceptual insight for the study of international donors' role in decentralization processes.

The book starts with a conceptual chapter authored by the editors on decentralization in MENA across space and time, beginning with the genesis of MENA statehood. Guided by a thorough historical analysis of the emergence of nation-states in the region, this chapter develops the conceptual approach for the analysis of decentralization processes. The authors suggest that decentralization is inspired, channelled, and instrumentalized by informal neopatrimonial elite networks on the national, regional, and local levels of government. Fiscal and budgetary policies are then introduced as empirical tools to investigate the gap between normative intents

2 For security reasons we conducted field work in three out of four countries. Shrinking political spaces in Egypt and the increasing repression of academics in the country did not allow us to do field research in Egypt (see chapter 3). 
and purpose of formal decentralization, such as local empowerment, and the diverging outcome and greatly more complex reality of decentralization.

In view of the importance of fieldwork to our study and the need for an exploratory approach, the empirical part begins with a chapter on the pitfalls and challenges of doing fieldwork research at the subnational level in MENA countries. As put forward by Miriam Bohn, Thomas Demmelhuber, and Erik Vollmann, field research in non-democratic contexts is problematic. Even prior to the Arab uprisings, the clustering of autocratic regimes in the MENA region held great challenges regarding the access to the field, access to data and archives, and the identification of potential interview partners or participants for survey research. In most cases, research was possible only within legal "grey zones", as official permissions to conduct research are difficult to acquire. For international scholars, access to the field was usually granted via tourist visas and fieldwork was conducted with the implicit tolerance of the security apparatus. Even so, among the research community there exists an implicit shared knowledge regarding the scope of possible research, restricted by "red lines" known to the informed researcher in the field. With the alleged murder of the Italian $\mathrm{PhD}$ student Giulio Regeni at the hands of Egyptian security forces in 2016 (Egyptian authorities have rejected all responsibility) and other cases of arbitrary imprisonment of international scholars in MENA countries (for example Matthew Hedges in the UAE 2018), the situation of academic research has settled into a new reality. As Grimm puts it: "Authoritarian Middle East regimes don't like academics" and this "trend signals a massive rollback of the auspicious research climate" (Grimm 2018). On the turn side, these developments have at least and last triggered debate on fieldwork conditions among academia, funding bodies, and multipliers of international cooperation. The goal is to attain a more sensible risk assessment when planning and doing fieldwork in MENA countries (Glasius et al. 2018; Grimm et al. 2020).

For the research on this book, these developments required us to look for a maximum return on insights we could gain through fieldwork. The empirical findings on the roles of neopatrimonial elite networks in the politics of decentralization and in fiscal policies are presented by Miriam Bohn and Erik Vollmann (both worked as research associates in the research project) from a comparative perspective in two separate chapters. Their contributions, which provide indicators for the degree of verifiable decentralization, are guided by our working hypotheses (see chapter 2).

The chapter on the role of neopatrimonial elite networks in decentralization is based on the premise that MENA politics are a product of for- 
mal-legal institutions entwined with informal rules that gain salience through highly personalized structures of power relations. Though the periphery has always been central to this type of personalized governance, the subnational dimension of neopatrimonialism has remained a lacuna in the comparative research literature on MENA states. ${ }^{3}$ In light of the revival of decentralization efforts and discourses following the Arab uprisings, Miriam Bohn and Erik Vollmann, however, argue that the analysis of the relationship between local governance reforms and neopatrimonialism is key to a better understanding of governance and policy formulation in the MENA region. Decentralization reforms have a significant impact on patron-client relations between the central and the subnational levels. They provoke a principal-agent problem, but also create a new set of incentives for a number of policies. Thus, a systematic analysis of central and subnational elite dynamics is essential to broaden the understanding of decentralization under neopatrimonialism. Both authors conclude that the country-specific interplay of central and subnational elite networks impacts the legal framing and the practical outcomes of decentralization processes, and vice versa.

The chapter on fiscal policies in times of decentralization builds on the same assumption, namely that the boom in decentralization rhetoric and action after 2011 were reactions to protests caused by long-standing local government malfunction and economic deprivation of the periphery. In all four investigated cases, the discourses and reforms use a language of "positive discrimination" and promise a reformed relationship between the center and the periphery. In theory, this should lead to an improvement of subnational administrative efficiency and an empowerment of the long-neglected periphery. In the setting of ambiguous legal contexts and high influence of traditional patron-client relationships within the central state level, decentralization reforms do not always result in the participative, democracy-enhancing, and reconciliatory model that governments and international donors advertise. The establishment of subnational institutions with sufficient and independent funds that allow the sovereign execution of tasks and fulfillment of rights is a necessary precondition for meaningful decentralization. Both authors show that fiscal decentralization is the litmus test for the willingness of political rulers to commit

3 Hertog $(2011,5)$ offers, for example, an inspiring narrative of state-building in Saudi Arabia since the 1930s relying on a "heterogenous system of formal and informal, rent-based clientelism in which vertical links" to the rapidly emerging central state level dominate. 
themselves to decentralization and for tackling the deficits of local governance in a region.

This book is above all the result of a research project investigating domestic politics in four countries. In order to capture the international dimension of the decentralization discourse, we invited Sylvia Bergh to contribute to our book. She analyzes the perspective and impact of international donors on decentralization reforms for the cases of Morocco and Tunisia. By focusing on two donors in two countries (World Bank and German GIZ), with five program/project case studies, Bergh illustrates that aid support does not operate in a linear continuum, but is dependent on several contextual variables and incentives. In other words, it matters what form aid takes and how it is delivered. Donors are aware of their role, but are convinced that the struggle for good governance is worth the deficits of decentralization efforts.

\section{Main findings: Decentralization, a theater of reform?}

For the examples of Morocco, Jordan, Tunisia, and Egypt, our findings illustrate a strong impact of agency and institutional design on the outcome of decentralization processes. Neopatrimonial elite networks matter to the content and roll out of decentralization strategies in the MENA region. There is also robust evidence that regimes are cautiously watching the unfolding dynamics of decentralization reforms in order to avoid unintended (and potentially threatening) consequences for regime stability and power balances. In other words, setting up the institutional design for decentralization does not preclude "reforms of the reform": As the Jordanian case shows, negotiations to revise decentralization laws are a continuous process. The intention of central governments is to minimize the side effects of local autonomy and to reduce political emancipation.

Our analysis of Morocco, Jordan, Tunisia, and Egypt reveals how different elite networks use formal and informal institutions within a decentralized state structure to maintain or widen their influence, resources, and power (see chapter 4). The empirical analysis also clearly illustrates that decentralization can constitute a "Pandora's box" to the political regimes, filled with intended and unintended consequences. Although in all four case studies decentralization is formally and informally designed to benefit the regime, the regimes are circumstantially hesitant to fully commit to the legal framework they have supported. Regimes fear the possibility that it could backfire and result in high transaction costs for the center. Based on numerous interviews, both Bohn and Vollmann present a trajectory 
showing how the monarchies Morocco and Jordan have spanned a solid network of patron-client relations between the center and the periphery across subnational state institutions. Through this network, the Jordanian regime closely observes the management of Transjordanian and Palestinian communities - overwhelmingly to the benefit of Transjordanian tribes. When decentralization affects this set-up, the Jordanian regime reacts with harsh repression or modified modes of cooptation. Subnational actors in Morocco are likewise carefully divided and controlled by a net of state agents, whose dominance over subnational councils remains unbroken. While party elites engage actively in elections and political competition, they are dependent on alliances with local notables, party coalitions and deference to the makhzen (the royal court as the powerhouse of the king and his closest associated elite groups) as well as its national and subnational representatives.

Though both Morocco and Jordan grant some minor autonomy to subnational institutions, formal and informal practices that can curtail the power of peripheral actors permanently play out in the background. In all four countries, elite rotation between major subnational positions is a common practice to contain the influence of certain individuals, especially that of governors with far-reaching powers. In all four cases, the structure of elite networks and their respective behavior affects the de facto outcome of decentralization. Bohn and Vollmann present robust empirical data, which illustrates that Jordan and Morocco are playing a sensitive balancing game and oscillate between the wish to appease the international community and to present themselves as reformers on the one hand, and the need for strategies to manage socio-political and economic conflict on the ground on the other. A decentralization reform deeply interferes with a country's patron-client structure and its outcome depends on the central and subnational elites' reactions. The competitive clientelism and gerrymandering that accompanies subnational elections, as well as elite capture, for example by corruption, easily twists the logic of a decentralization reform.

Our research on the four countries shows that the era of fiscal decentralization has not yet arrived in the MENA region (see chapter 5). While all cases in our sample use the language of decentralization and subnational finance, meaningful fiscal decentralization has yet to emerge from halfhearted legal changes and official rhetoric. Though comparable and reliable data are still rare, we can detect some trajectories in absolute spending when we compare the subnational fiscal situation of Egypt, Jordan, Morocco, and Tunisia before and after the Arab uprisings. In a meticulous investigation of fiscal data, Vollmann and Bohn show that all countries in- 
creased subnational state expenditures since the 1990s - boosted by IMF structural adjustment programs. It is remarkable that additionally Morocco and Tunisia record significant progress after 2011. Tunisia's path to decentralization is still inconclusive, but it suggests a radical break with the hyper-centralization during the years of Ben Ali's regime. In Jordan and Egypt, however, the usual annual fluctuations of subnational expenditures remained in place even after 2011. Far-reaching fiscal decentralization could have a significant impact on pre-existing neopatrimonial networks between the center and the local level. The Jordanian regime is not willing to go down that road at present. All in all, the research by Vollmann and Bohn presents robust data that support our basic assumption that fiscal decentralization is the litmus test for the willingness of the center to commit itself to decentralization.

Jordan, Tunisia, and Morocco have all emphasized that the regional level has to play a central role within their reform packages, but only Morocco has chosen the path of meaningful regionalization and has thus fully left the "stage of a mere reform theater". This decision is beginning to show in the financial allocations the Moroccan regions receive. Nonetheless, the bulk of subnational spending, most of the revenue generation, and the largest share of salaried employees remain at the local level. If the regions are meant to become more than investment hubs at the hands of national initiatives and central state actors, Morocco needs to further accelerate its regional financial decentralization.

Regional disparities are central to the decentralization agendas in all four countries. The analysis suggests that decentralization is used in different ways to target the center-periphery nexus. Surprisingly, Tunisia still seems to uphold its preferential treatment of the capital and the Sahel, the traditional origin of its political elites, when we compare per capita expenditures of local councils. While Morocco's central northern regions also seem to be the continuous winners of subnational council expenditures in absolute terms, the per capita analysis shows a more nuanced picture: Strategically important peripheral regions such as the Western Sahara or the conflict-prone Oriental region (on the border to Algeria) spend more financial state resources per capita than the northern center. Political redistribution also occurs in Jordan: Zarqa, Irbid, and the capital Amman have the largest percentage of Palestinian communities amongst all Jordanian governorates. The authors' evaluation illustrates that majority-Transjordanian rural governorates traditionally connected to the regime receive larger amounts per capita than Zarqa and Irbid, the two largest and most urbanized governorates after Amman. 
The data presented by Vollmann and Bohn provide robust evidence that fiscal decentralization in MENA suffers from overwhelming dependence on central state transfers, weak subnational revenue generation, and problems with (local) tax collection. Combined with strong administrative oversight and general reservations of central actors and ministries towards subnational entities, the fiscal autonomy of subnational governments is small in all countries. Therefore, as the cases of Morocco, Tunisia and Jordan suggest, the capacity of subnational governments and their willingness to spend the small amounts they are provided with is limited.

Subnational governments thus often seem ill-equipped to contribute to the success of decentralization reforms in a meaningful way. Better human and financial resources as well as improved implementation capacities are crucial for successful subnational governance. A change in political culture that makes political success and autonomous decision-making less extraordinary at the subnational level is also necessary. Political cultural change has to be accompanied by convincing new regional narratives for which we found but scarce evidence. Strong political will of the central regimes would be necessary to move reform projects forward. Without a doubt, this would challenge both established neopatrimonial networks and assume the political conviction of MENA regimes that decentralization is the way forward. We have found no circumstantial evidence that such a development exists, or that such a crucial turning point might manifest in the near future.

In times of the COVID-19 pandemic, the political impetus for change is under tremendous pressure. The crisis has served as an excuse for re-centralizing certain powers under the pretext of fighting the virus. Yet, as the chapter authored by Bergh demonstrates, decentralization debates in the countries are interwoven with international donor programs that - depending on their loan volumes - have a significant impact on the changing center-periphery relations. In the donors' view, greater autonomy should be allocated to subnational levels that hold a significant potential for local citizens to challenge neopatrimonial networks.

\section{Outlook - a roadmap for further research}

The scope of our research and the robust results derived from our qualitative and quantitative data gives some insight into potential trajectories for further research. First, informal institutions are crucial to studying the role of neopatrimonial networks. At the same time, their analysis is the most difficult task: They are informal, ever changing, fuzzy, vague, and complex 
by definition. Fieldwork produces elite maps, but only limited information on power relations inside neopatrimonial networks and the parallel world they embody next to traditional state institutions. Even in "normal times" this is a major challenge for empirical research. When the transparency of decision-making processes further erodes and power struggles move behind the scenes in times of crisis, it becomes an insurmountable obstacle. The reality of shrinking political spaces and the consistent resilience of autocratic regimes will certainly remain a challenge for future research.

Second, fiscal policies haven proven to be a promising indicator and starter to trace the scope, quality, and outcome of decentralization. Additional policy fields might also offer promising entry points for future research, such as the health sector, infrastructure or public services on the subnational levels. Everything that immediately affects the living conditions of the general population can locally and regionally provoke the question: Where is our institutional access to representation and decisionmaking?

Third, MENA governments and regimes are learning from each other when it comes to strategies and modes of regime survival. Are they also learning regarding the implementation of decentralization strategies? The conceptual approaches derived from the international dimension of authoritarianism (in particular diffusion theory) might offer tools to trace possible emulation effects among MENA countries.

Fourth, another crosscutting issue in our sample was the common challenge all MENA governments have been facing when dealing with electoral cycles at the local level following decentralization efforts. They were all challenged by the success of actors from the spectrum of Political Islam. On the one hand, there seems to be a trend to curtail these dynamics by relying on various repressive measures. On the other hand, our results hint that moderate Islamists are also looking abroad for inspiration or best-practice models from like-minded Islamist groups, organizations, and parties. Systematic comparative research on this topic is still deficient.

Fifth, based on the exploratory research on Morocco, Tunisia, Egypt, and Jordan, the MENA region might offer an interesting context to expand the sample by using a fuzzy-set comparative qualitative analysis that also includes testing additional variables and an interregional perspective for Sub-Saharan cases.

These potential avenues of further research show that the scholarly debate on decentralization in the Middle East and North Africa has just begun with an ever growing "to-do list". A debate on meaningful decentralization is always also a debate on the quality of democracy. Decentralized 
rule without corresponding decision-making by elected representatives is difficult to imagine. As the experience of the OECD world shows, this first step to regional and local empowerment is much less dangerous to the ability of the center to govern than, for example, the experiences of France or Poland illustrates. However, this insight also tells us that the regime type matters and the involved elites matter even more.

\section{References}

Busse, Jan, and André Bank. 2021. "MENA Political Science Research a Decade after the Arab Uprisings: Facing the Facts on Tremulous Grounds." Mediterranean Politics, online first. doi: 10.1080/13629395.2021.1889285.

Demmelhuber, Thomas, Roland Sturm, and Erik Vollmann. 2020. "Decentralization in the Arab World: Conceptualizing the Role of Neopatrimonial Networks.” Mediterranean Politics 25 (4): 499-521. doi:10.1080/13629395.2018.15593 91.

Eaton, Kent, Kai Kaiser, and Paul J. Smoke. 2010. The Political Economy of Decentralization Reforms. Implications for Aid Effectiveness. Washington, DC: World Bank.

Glasius, Marlies, Meta de Lange, Jos Bartman, Emanuela Dalmasso, Aofei Lv, Adele Del Sordi, Marcus Michaelsen, and Kris Ruijgrok. 2018. Research, Ethics and Risk in the Authoritarian Field. Cham: Palgrave Macmillan.

Grimm, Jannis. 2018. “Authoritarian Middle East Regimes don't like Academics Ask Matthew Hedges.” Open Democracy, November 22. Accessed March 11, 2021. https://www.opendemocracy.net/en/policing-research-shifting-tides-for-mi ddle-east-studies-after-arab-spring/.

Grimm, Jannis, Kevin Koehler, Ellen M. Lust, Ilyas Saliba, and Isabell Schierenbeck. 2020. Safer Field Research in the Social Sciences. A Guide to Human and Digital Security in Hostile Environments. London: Sage.

Harb, Mona, and Sami Atallah. 2014. "Decentralization in the Arab World Must be Strengthened to Provide Better Services.” LCPS Policy Brief (11). Accessed March 11, 2021. http://www.lcps-lebanon.org/publications/1401092788-policy_brief_11 _lcps.pdf.

Harb, Mona, and Sami Atallah. 2015. "An Assessment of Decentralization and Service Delivery in the Arab World.” In Local Governments and Public Goods: Assessing Decentralization in the Arab World, edited by Mona Harb and Sami Atallah, 229-234. Beirut: LCPS.

Harguindéguy, Jean-Baptiste P., Alistair Cole, and Romain Pasquier. 2019. "The Variety of Decentralization Indexes: A Review of the Literature.” Regional \& Federal Studies 31(2), 185-208. doi:10.1080/13597566.2019.1566126.

Hertog, Steffen. 2011. Princes, Brokers, and Bureaucrats. Oil and the State in Saudi Arabia. London: Cornell University Press. 
Heydemann, Steven. 2007. Upgrading Authoritarianism in the Arab World. The Saban Center for Middle East Politics Analysis Paper 13. Accessed March 11, 2021. https:// www.brookings.edu/research/upgrading-authoritarianism-in-the-arab-world/.

Hoffmann, Anja, Malika Bouziane, and Cilja Harders. 2013. Local Politics and Contemporary Transformations in the Arab World. Governance Beyond the Center. Basingstoke: Palgrave Macmillan.

Keman, Hans. 2000. "Federalism and Policy Performance. A Conceptual and Empirical Inquiry." In Federalism and Political Performance, edited by Ute Wachendorfer-Schmidt, 196-227. London: Routledge.

Kherigi, Intissar. 2017. "Devolving Power After the Arab Spring: Decentralization as a Solution.” Al-Sharq, March 30. Accessed March 11, 2021. https://research.sh arqforum.org/2017/03/30/devolving-power-after-the-arab-spring-decentralization -as-a-solution/.

Shalaby, Marwa, Chagai Weiss, Ellen Lust, Kristen Kao, Erik Vollmann, Sylvia I. Bergh, Ezra Karmel, Miriam Bohn, Intissar Kherigi, and Zeynep Kadirbeyoglu. 2020. The Dynamics of Decentralization in the MENA: Processes, Outcomes, and Obstacles. GLD Working Paper No. 31. Gothenburg: GLD.

Vollmann, Erik, Miriam Bohn, Roland Sturm, and Thomas Demmelhuber. 2020. "Decentralisation as Authoritarian Upgrading? Evidence from Jordan and Morocco." The Journal of North African Studies: 1-32. doi: 10.1080/13629387.2020.17 87837. 
